\title{
Nuevas evidencias de Arte Rupestre en Quebrada Verde, valle bajo del río Lurín
}

Teddy Abel TRASLAVIÑA ARIAS / Universidad Científica del Sur

\begin{abstract}
Resumen
El texto que a continuación presentamos esboza los avances preliminares del registro general de sitios arqueológicos dentro de los límites de Quebrada Verde, con motivo de una investigación en curso, dentro de una zona de lomas ubicada en el valle bajo del Río Lurín. Dentro de este registro, llama la atención un grupo de abrigos rocosos que contiene representaciones rupestres pictóricas y que ha pasado desapercibido en las escasas investigaciones en el lugar. Tales evidencias son sumamente significativas dada su carencia en zona costera, debido a la ausencia de soporte geológico y condiciones adecuadas, razón por la cual hasta el momento sólo se contaría con dos zonas conocidas distribuidas tanto en la Costa Central (Lachay e Iguanil) como en la Costa Norte (Ochipitur).
\end{abstract}

\section{Palabras Clave:}

Costa Central, Valle de Lurín, lomas, Arte Rupestre.

\section{Abstract:}

This article presents preliminary field data of a survey into the Quebrada Verde Basin, in the occasion of a research in course, located in a lomas' zone, in Low Lurin Valley. A group of rockshelters that contain evidences of Rock Art, a sui generis characteristic on the coast, are at the moment, one of the most interesting data because the knowledge about that is only restricted to highlands. The unique evidences on coastal zone are, in that context, in North Coast (Cerro Ochipitur) and Central Coast (Lachay and Iguanil).

\section{Key words:}

Central Coast, Lurín Valley, lomas, Rock Art. 


\section{Ubicación y aspectos geográficos}

El área de estudio se encuentra en la margen derecha del valle bajo del río Lurín, a 7 kilómetros de la línea de playa y a $30 \mathrm{~km}$. al sur del valle del Rímac. En dicha zona yace el Centro Poblado Rural Quebrada Verde, perteneciente al distrito de Pachacamac (Figura 1).

El valle bajo del río Lurín se inicia en Panquilma y se extiende hacia el Océano Pacífico. Esta sección comienza con un ancho de un kilómetro y continúa ampliándose hasta alcanzar 15 kilómetros de ancho en su cono de deyección (Matos y Portugal, 1964, p. 128).

Dentro de la clasificación de Köeppen el valle bajo se adscribe al Clima Seco que corresponde a las letras BW, que es del tipo "Desértico casi sin Iluvias" (B: desértico; W: casi sin lluvias), lo que además, en base a la adaptación de este sistema que hace Carlos Nicholson, la zona baja se encuentra dentro del tipo de clima Sub-tropical Costanero que se extiende desde el río Chira, en Piura, hasta la frontera con Chile (Ibídem, pp. 128 y 129), clasificación compartida también por G. Petersen (Bonavía, 1991, p. 28). Esta amplia zona se caracteriza por precipitaciones que fluctúan entre una mínima de $0 \mathrm{~mm}$. y una máxima de $300 \mathrm{~mm}$. de lluvias anuales (Matos y Portugal, op. cit., p. 129). La temperatura media para el sector bajo del valle de Lurín es de $19^{\circ} \mathrm{C}$, lo que corresponde al tipo BWh (h: temperaturas medias anuales superiores a $18^{\circ} \mathrm{C}$ ) (LoC. cit)., sin embargo Bonavía adscribe la zona, con mayor precisión, a un tipo BWhn, donde n se refiere a "neblina abundante" (Bonavía, 1991, p. 28). Según explica Bonavía, este fenómeno depende de las corrientes oceánicas y de la gran cadena andina.

De este modo, durante el invierno del Hemisferio Sur, la Corriente Peruana se presenta desde Piura hacia la costa chilena. Dicha corriente posee aguas templadas que tienen una temperatura de entre $18^{\circ}$ a $19^{\circ}$ C a causa de la emergencia de las aguas, situación que produce una inversión de temperatura en el aire caliente tropical, que pasa a enfriarse. Debido a esta situación se produce una estratificación de nubes que es causante a su vez de las lloviznas o garúas (excepto en temporadas de ENSO, siglas de El Niño-Southern Oscillation). Dichas nubes llegan a ser arrastradas por los vientos a más de $50 \mathrm{~km}$. hacia el interior de los valles (Ibídem, pp. 28 y 29).

El virazón, o brisa marina, sopla en esta zona desde SSW, elemento importante en la humedad reinante en la zona. Estos vientos son más intensos en los meses de abril, mayo y también en julio (Matos y Portugal, 1964, p. 129). De este modo la humedad se propaga y provoca el fenómeno conocido como lomas, el cual coincidentemente está expresado en la toponimia de la zona de estudio: Quebrada Verde. 


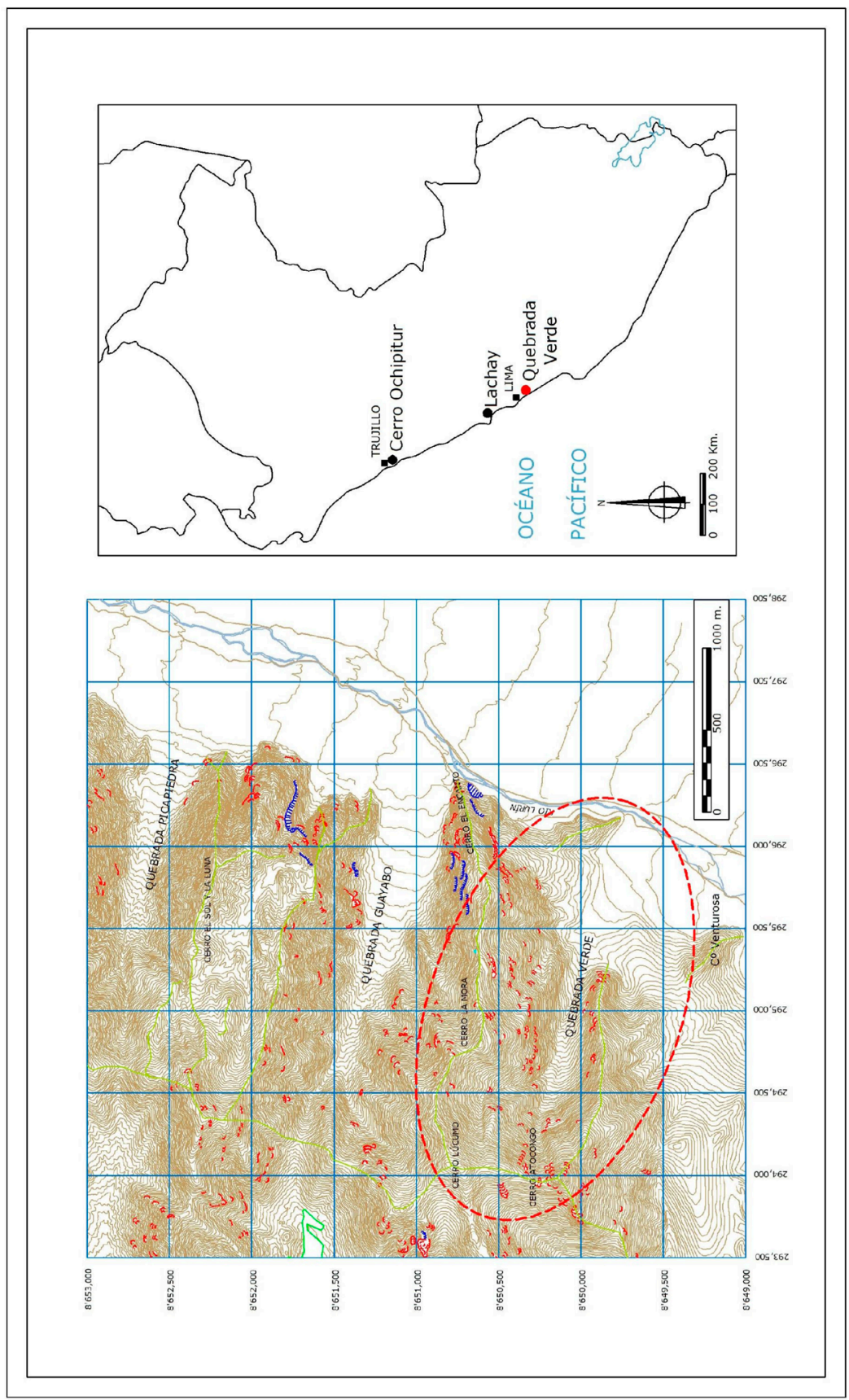

Figura 1. Ubicación de las zonas arqueológicas con arte rupestre pictórico en la costa peruana. La zona de estudio está en el óvalo rojo. Mapa digitalizado tomando como referencia la Carta Nacional - hojas 25-j 43 y 25-j 53 - para la ubicación de la zona de estudio, la ubicación de Lachay tomando como referencia a Guffroy $(1999,68)$ y a Castillo Benites $(2006,81)$ para Cerro Ochipitur. Elaboración del autor. 


\section{Aspectos geológicos y fisiográficos}

Quebrada Verde se forma a partir de una cadena de cerros, propia del Batolito Costanero. Dicha cadena de cerros se emplaza entre el gran depósito eólico de arena del Cuaternario, que se extiende desde la Tablada de Lurín hasta el cono de deyección de Quebrada Verde, y los depósitos aluviales cercanos al cauce del río Lurín (INGEMMET, 2002).

A continuación, de modo general se tendrá en cuenta una zonificación que responde a los componentes de la quebrada en estudio, su naturaleza y potencialidades, siendo diferenciadas del siguiente modo (Figura 2):

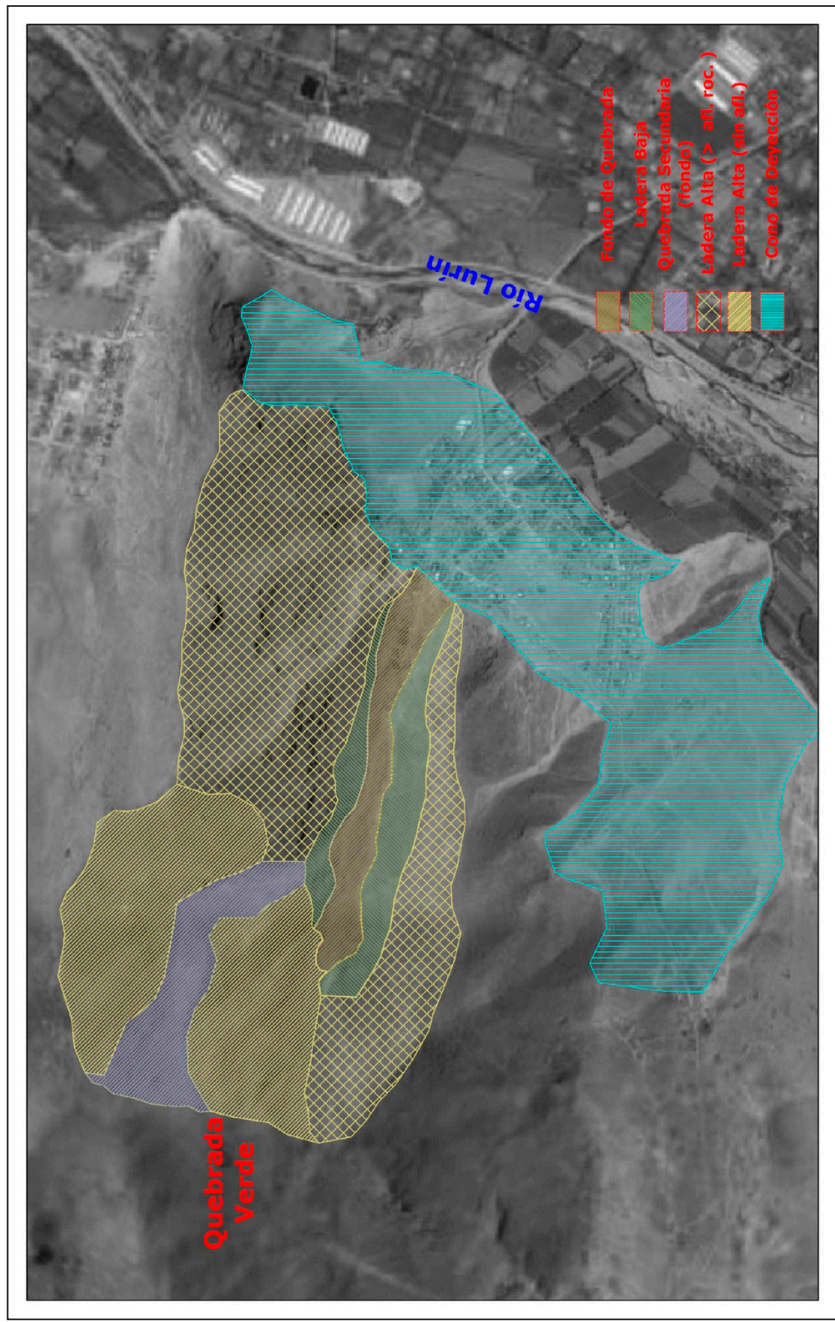

Figura 2 . Foto satelital en la que se muestra la zonificación hecha para el registro de los sitios arqueológicos en Quebrada Verde. Modificado de la versión en línea del programa Google Earth versión 2007. 
Fondo de Quebrada. Conformada en su mayoría por "suelos oscuros" de probable naturaleza orgánica, además de depósitos de tipo coluvial, es decir por el desprendimiento de las rocas de las laderas hacia el fondo del cauce (Ing. Eddy Vicharra Cuadros, comunicación personal, 4 de marzo del 2006). Actualmente esta zona no se utiliza para cultivo por existir en su mayoría rocas de distintos tamaños, que afloran muy superficialmente, sin embargo se aprecian algunos arbustos propios de lomas, plantas muy pequeñas y algunas cactáceas. Este tipo de suelos es de consistencia plástica al contacto con el agua.

Laderas Bajas. Conformada en su mayoría por "suelos arcillosos" de color claro (marrones), además de algunos afloramientos rocosos dispersos (Ing. Eddy Vicharra Cuadros, comunicación personal, 4 de marzo del 2006). Actualmente esta zona es utilizada para plantar algunos árboles, sin embargo estos no han florecido probablemente por ser especies foráneas. El tránsito actual es muy restringido por estas zonas, salvo la presencia de un camino que forma parte del circuito turístico de la zona. Existe escasa vegetación dependiendo de la temporada en que se encuentre. La consistencia de dichos suelos es plástica, pero en menor medida que en el fondo de quebrada por las inclusiones de pequeñas piedras que posee.

Laderas Altas. Compuesta por intrusivos de composición Leucogabroidea y Granodiorítica. La roca ha sufrido una escamación concéntrica o exfoliación catafálica, razón por la cual se descompone por capas, de modo similar a una cebolla (ing. Eddy Vicharra Cuadros, comunicación personal, 4 de marzo del 2006). De otro lado, por acción eólica y del intemperismo, se han labrado cavidades en las paredes de los cerros formados de estos intrusivos (Castañeda Mungi, 1973). Además, por su mayor contenido de Plagioclasas (mineral con contenido en silicatos) suele transformarse en arcilla al contacto con la humedad (Ing. Eddy Vicharra Cuadros, comunicación personal, 4 de marzo del 2006). Si bien existen sectores inaccesibles o de difícil acceso en esta zona, puede accederse a ella por algunos lugares cuya pendiente no es tan pronunciada. A pesar de los afloramientos rocosos, la humedad presente permite la existencia de plantas rastreras que aprovechan algunos espacios vacíos entre las rocas y las laderas.

Cono de Deyección. Se conforma de depósitos aluviales provenientes del arrastre provocado por el Río Lurín y depósitos eólicos, ambos del Cuaternario (INGEMET, 2002). Actualmente en este lugar se encuentran algunas chacras de cultivo y es en donde se asienta el CPR Quebrada Verde. Si bien no se aprecia vegetación propia de esta zona, en el año 2003 pudimos apreciar que la vegetación superficial de lomas se extendía hacia algunos sectores del arenal, lo que sugiere que esta situación no fue nada extraña en años pasados. En la zona donde se ubica el cono de deyección de la quebrada se pueden observar dos cerros ubicados a cada lado: hacia el norte uno de nombre desconocido y hacia el sur otro denominado Cerro Venturosa. 


\section{Investigaciones previas}

Las investigaciones realizadas en la zona prácticamente son inexistentes, teniendo en cuenta que hasta el momento un lugar que no posee registro oficial alguno. Sin embargo se puede citar el registro de evidencias cercanas que van desde el sitio Venturosa, reportado por Max Uhle, hasta las evidencias reportadas por Engel y el equipo del CIZA.

En su libro Pachacamac (1903) Max Uhle reporta una zona de entierros conocida como Venturosa. Uhle adscribe a las evidencias encontradas como del periodo Inca u Horizonte Tardío (1450 d.C. - 1532 d.C)., sin embargo se refiere a la cerámica encontrada de la siguiente manera: "(...) their type being the same as those upon the arybals of the Inca time, and clearly an imitation." (Uhle, 1991 [1903], p. 72), es decir que se trataba de una imitación o una factura local de la cerámica Inca.

De otro lado, años más tarde, Engel, interesado en las zonas de loma, dice lo siguiente al respecto de su visita a la zona: "La loma, ubicada en las alturas que dividen los cauces de los ríos Rímac y Lurín, era todavía muy extensa y en vida hace unos años. Quedaban como $25 \mathrm{~km} 2$ visibles. Hoy en día los invasores han penetrado en la zona y pronto no quedará nada de vegetación. Estas invasiones impiden una investigación seria." (Engel, 1988, p. 33). Es así que Engel se refiere a la zona de Atocongo y la Tablada de Lurín, registrando dos sitios en Quebrada Verde, a los que denomina "corrales" y "desperdicios", de los que no brinda mayores referencias.

Como parte de los antecedentes para la zona hemos de mencionar un reconocimiento de superficie monitoreado por la arqueóloga Luisa Díaz', gracias al cual se hallaron parte de los sitios arqueológicos que se reportan ahora.

\section{Registro General de Sitios Arqueológicos}

A continuación se muestran las descripciones y ubicación generales de los sitios encontrados de acuerdo a las zonas explicadas (Figura 3):

Fondo de Quebrada. La evidencia en esta zona se restringe a algunos muros de dimensiones extensas con presencia de algunas divisiones en su transcurso. El fondo de quebrada es estrecho y a lo sumo permite, dada su condición de depósito coluvial, distinguir con dificultad estos muros. No se encontró material asociado a estos, salvo algunos minúsculos fragmentos de cerámica que no brindaron mucha información. Resulta desconcertante la

\footnotetext{
${ }^{1}$ Como parte de la asignatura de Métodos en Arqueología I, la Lic. Luisa Díaz Arriola, docente de la Universidad Nacional Mayor de San Marcos, decidió desarrollar las prácticas de campo en el valle bajo de Lurín. Luego de visitar las tres quebradas adyacentes se eligió a Quebrada Verde como centro de labores. Se formaron varios grupos de estudiantes, a uno de los cuales perteneció el autor. Los recorridos en la zona se hicieron durante el desarrollo del curso, en la segunda mitad del año 2003, cada fin de semana entre los meses de octubre y noviembre. A pesar de esto, nunca se hizo registro oficial alguno para la zona.
} 
Nuevas evidencias de Arte Rupestre en Quebrada Verde, valle bajo del río Lurín

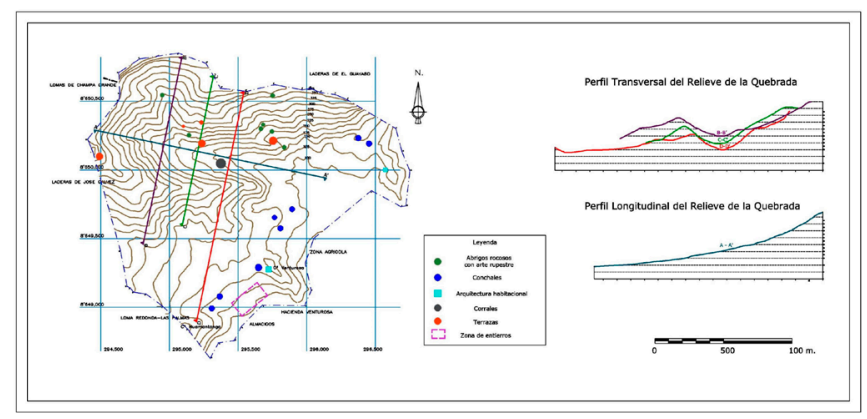

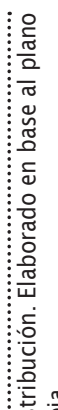

$>$ 등

ซ్ ซ్

응

응 즘

뭉

훙은

安

는

을

d

을

$\frac{7}{2} \frac{\pi}{2}$

중

ํํำ

뜨흥

웡

o

으

叫

흠음

पू

峁

ㅇㅇㅇ

응 우

논

을 온

응

$\frac{2}{2}$

需

흔

늘

Ơ

는 는

ত ग

这

ธั ฮ

음 음

중

mi

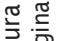

은 음 
presencia de un muro muy largo que a primera impresión delimita el fondo de la quebrada y lo diferencia de la ladera baja Norte. Este muro además sigue la dirección de los rastros de una escorrentía que se pueden observar en esta zona (Figura 4).

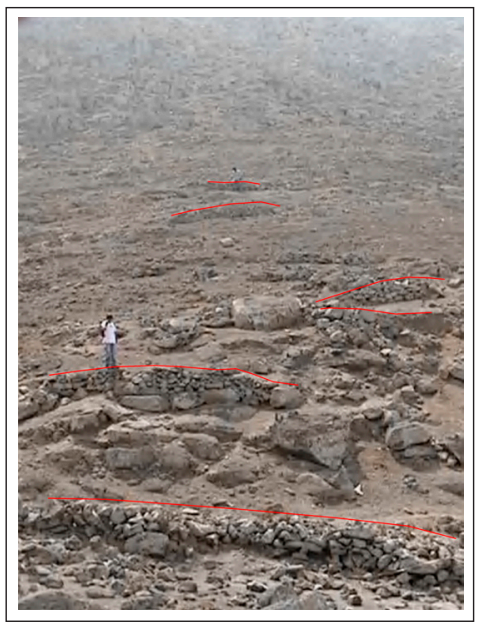

Figura 4. Vista de la parte baja de la ladera izquierda. Señalados en rojo se observan los muros, el más bajo corresponde al muro extenso en el fondo de la quebrada principal, mientras que los otros corresponden a terrazas ( 23 de abril del 2006, foto del autor).

Laderas Bajas. Para esta zona, la evidencia consta básicamente de muros de pirca de formas cuadrangulares e irregulares que podrían haber cumplido la función de corrales. Estos se sitúan únicamente en la ladera baja sur, que es la zona más extensa de este tipo, además de ser la de menor pendiente en este sector (Figura 5).

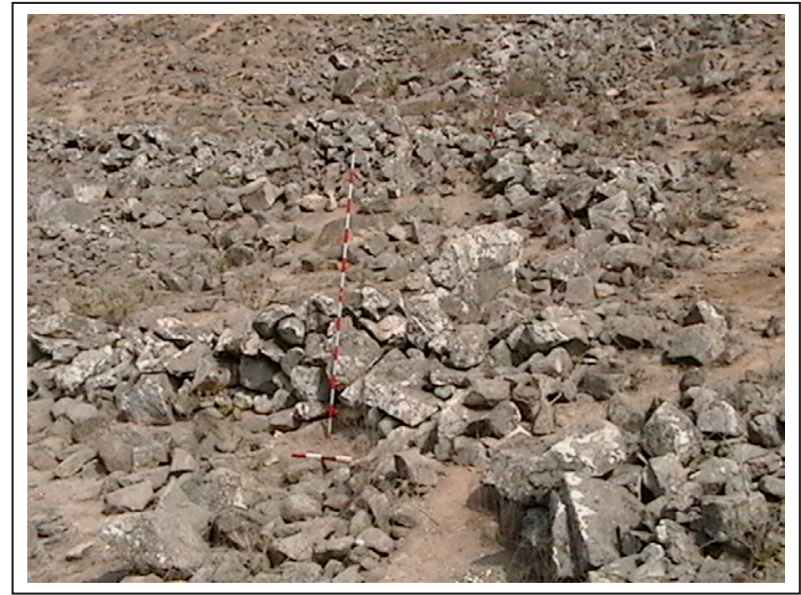

Figura 5. Vista de algunos muros poco conservados que corresponden a corrales ubicados en la ladera derecha baja. Cada división de la escala corresponde a $10 \mathrm{~cm}$. (23 de abril del 2006, foto del autor). 
Laderas Altas. En esta zona, al prevalecer los afloramientos rocosos, predominan también los abrigos en general y de manera especial aquellos que contienen representaciones rupestres pictóricas (Figura 6). Del mismo modo, además de presentarse los abrigos, en esta zona no se encuentran otro tipo de evidencias distintas a terrazas, lo que nos sugiere una preocupación por tratar de hacer frente a lo pronunciado de la pendiente en esta zona. Sin embargo podemos observar que prácticamente no existe evidencia cultural en la ladera alta sur, salvo un conjunto de terrazas en la cumbre del Cerro Atocongo (Figura 7), debido a, como lo dijimos líneas arriba, la mayor incidencia de zonas de pendiente muy pronunciada o terrenos muy escarpados, ya que los afloramientos rocosos que ocupan esta zona tienden a ser verticales al igual que la ladera en su conjunto.

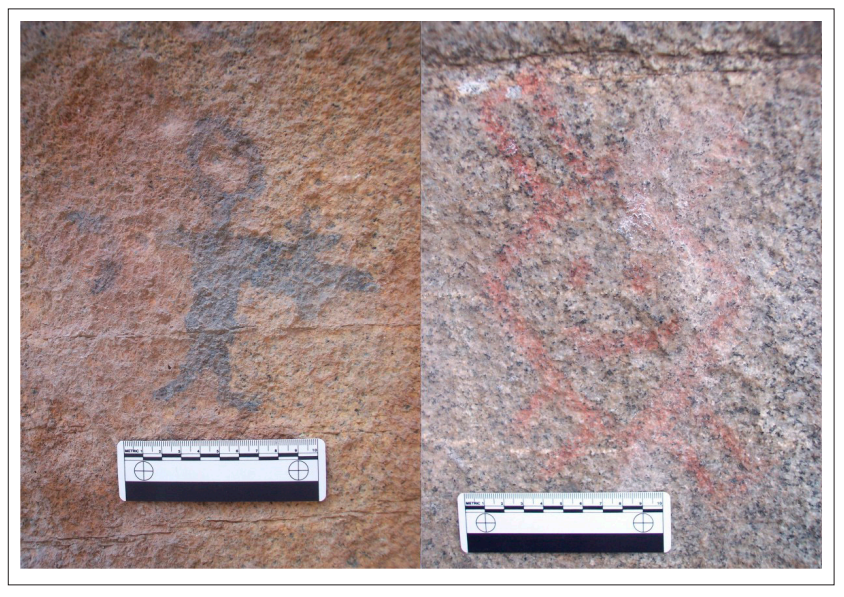

Figura 6 . Figuras en tonalidad negra (derecha) y roja, ubicada en uno de los abrigos rocosos. Las escalas miden $10 \mathrm{~cm}$. (11 de junio del 2006, foto del autor).

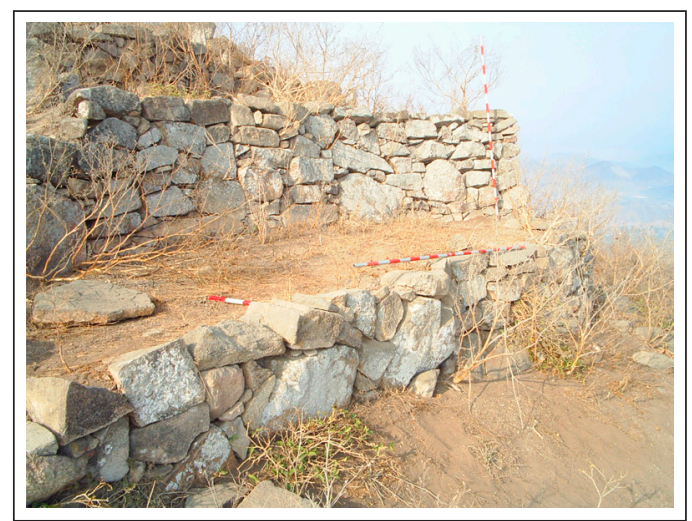

Figura 7. Vista de terrazas en la cumbre del cerro Atocongo. Cada división de las escalas corresponde a $10 \mathrm{~cm}$. (22 de febrero del 2006, foto del autor). 
Cono de Deyección. A pesar de parecer plana, por el mismo hecho de que la zona en su mayoría está compuesta de arena eólica, el cono de deyección tiende a una pendiente relativamente pronunciada y ondulada. A pesar del asentamiento actual hemos podido encontrar que la zona en su conjunto no ha sufrido modificaciones lamentables debido a que aquí el proceso de urbanización se viene dando de manera muy lenta. Gracias a esto hemos podido ubicar algunos conchales o zonas de concentración de valvas de moluscos (Figura 8), en su mayoría Mesodesma donacium ("machas"), además de fragmentos de cerámica, diagnósticos y no diagnósticos, que han ayudado a proponer una fecha tardía de la mayoría de sitios con evidencia material.

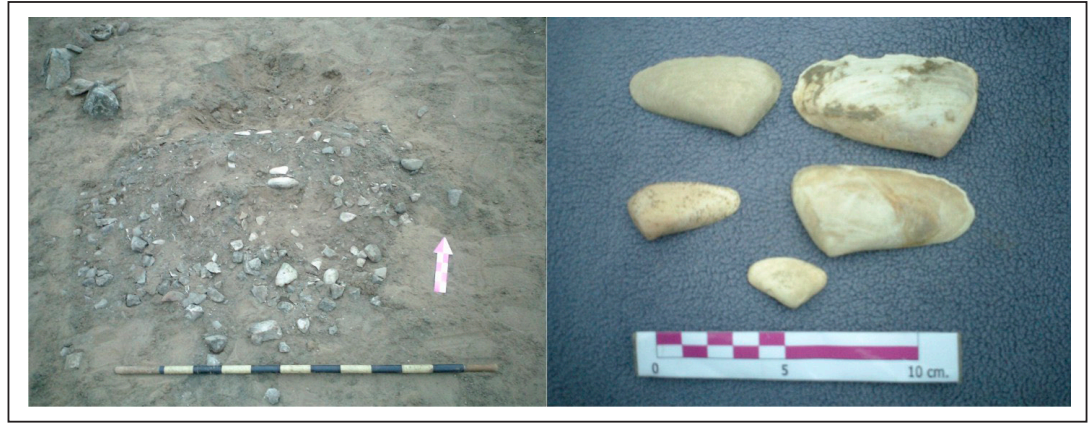

Figura 8. Vista de un conchal con algunas evidencias de "machas" (Mesodesma donacium). Cada división de la escala de la izquierda es de $10 \mathrm{~cm}$. la escala de la derecha mide $10 \mathrm{~cm}$. (5 de junio del 2005, foto del autor).

No podemos dejar de mencionar a los cerros aledaños al cono de deyección:

Cerros Aledaños. Estos cerros son dos, dispuestos cada uno a un extremo del cono de deyección. En la cima del que se encuentra al norte hemos podido observar que existe evidencia muy escasa de ocupación, ya que encontramos un solo alineamiento de piedras que pudo haberse tratado de un muro, pues además de este elemento encontramos cerámica muy fragmentada en las inmediaciones. El hecho de encontrar sólo un muro, creemos, se debe a las plantaciones de una línea de árboles que

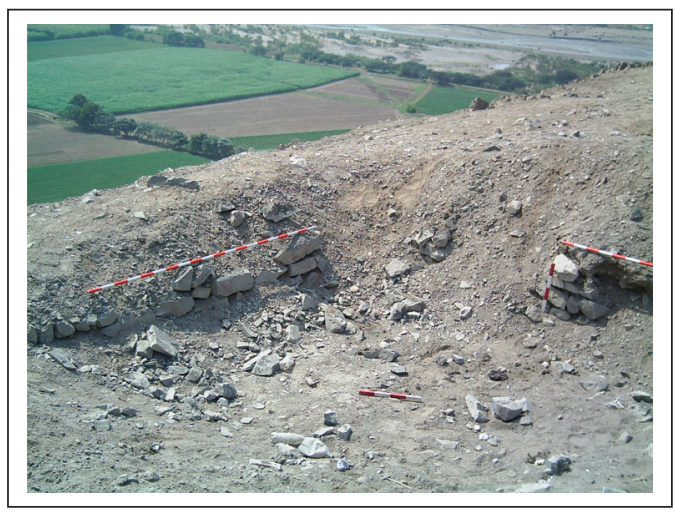

Figura 9. Vista de la cima del Cerro Venturosa. Nótese a partir de la disposición de los muros que se estaría configurando un pequeño recinto. La división de las escalas es de $10 \mathrm{~cm}$. (15 de abril del 2006, foto del autor). 
dividen este cerro por la mitad para cuya remoción tuvo que haberse hecho zanjas, con lo que destruyeron lo que existió en la cima de este cerro.

En el caso del cerro que se encuentra al sur (Cerro Venturosa), pudimos observar la presencia de una serie de muros que conformaban espacios cerrados a modo de recintos (Figura 9). También encontramos escaso material cerámico y malacológico.

\section{Sobre el "Arte Rupestre", su estudio y algunas implicancias}

Los sitios arqueológicos con arte rupestre, en el Perú, han sido estudiados aún de manera muy somera. Las investigaciones realizadas, hasta ahora, han efectuado, en su gran mayoría, sólo registros e inventarios de las zonas en donde se concentran (Núñez Jiménez, 1986; Muelle J. y Ravines R., 1986; Hostnig, 2003). Esta situación se debe a que este tema involucra muchas dificultades, dentro de las cuales el registro es una de ellas. El registro de Arte Rupestre se torna engorroso muchas veces, ya que no basta con el registro fotográfico, sino que en muchos casos se tiene que hacer el calco de las figuras, recomendándose este procedimiento exclusivamente en petroglifos mas no en pinturas, ya que la fricción puede causar deterioro en éstas, según hace notar el especialista Jean Guffroy (1999, p. 21)². Sin embargo una foto mal tomada puede distorsionar la imagen, creando como un apresurado y mal calco, lo que mellaría las posteriores explicaciones sobre este tema. En el caso específico de las pinturas rupestres, el hecho de precisar el color de la sustancia con el que se realizaron dichos trazos y dibujos podría ayudar a identificar representaciones cercanas y tentar una explicación asociativa, ya que al registrar un mismo tono de color probablemente podríamos proponer que la materia prima de la que provino el pigmento sea de similar origen. Asimismo la forma de plasmar una pintura en roca no siempre será la misma, ya que pudieron utilizarse distintos elementos, desde un elaborado pincel, hasta las manos de los individuos. Es así que tener en cuenta estos aspectos pueda quizás ayudar a un mejor entendimiento del tema.

Otro de los problemas que se presenta es el asociarlos a algún tipo de material para tentar explicaciones respecto tanto a su origen cultural como cronológico, ya que las pinturas y petroglifos, si bien son elementos culturales, no aparecen asociados directamente con otros materiales como sí ocurre con los objetos que se encuentran en los estratos de una excavación, pues por más que existan elementos cercanos, espacialmente hablando, no podemos asegurar con certeza una asociación cultural o cronológica. Este es quizás uno de los mayores impedimentos que se tiene para hacer estudios de Arte

\footnotetext{
2 "Recordamos aquí algunas reglas de oro que no debe olvidar ninguna persona interesada. El caso de las pinturas: no tocar con los dedos, no aplicar directamente un calco sobre las paredes, tomar buenas fotografías (con luz natural o artificial) y trabajar después sobre ampliaciones o proyecciones. En cuanto a los petroglifos: no aplicar tiza (esta costumbre demasiado difundida, hasta en los profesionales, es causa directa de la mutilación de centenares de figuras, entre las más bellas del patrimonio peruano). Si se quiere hacer fotografías: armarse de paciencia y esperar una buena luz. Lo más cómodo y más preciso sigue siendo levantar un calco con una hoja plástica transparente y un plumón."
} 
Rupestre, ya que, si bien son temas de interés de la Arqueología, no se produce tanta investigación como en otros campos o temas de nuestra Ciencia, siendo usualmente abordado por aficionados.

En conclusión, en la mayoría de los casos, uno de los problemas mayores que acarrea estudiar un sitio de este tipo es que no nos es posible asociarlos cronológicamente a periodo alguno, tan sólo tenemos algunas interpretaciones, pero ninguna comprobable de manera material.

Es lamentable que no se efectúen más investigaciones al respecto ya que las representaciones rupestres son prácticas de tipo generalizado. Estas evidencias se encuentran en todo el territorio peruano, tanto agrupadas cuanto de manera aislada y dispersa, lo que no ha permitido asociar su presencia a actividad humana alguna, ya que esta práctica se siguió desarrollando aún después del arribo español a este continente.

Dado esto, somos conscientes de que los estudios de arte rupestre conllevan cierta dificultad en cuanto a establecerlos en tiempo y espacio cultural adecuados.

A pesar de contar con estas limitaciones, creemos necesario hacer un buen registro de estas manifestaciones, precisamente para poder integrarlas a las demás y acercarnos a una explicación más completa de los procesos culturales. Esto sólo se logrará mediante un registro pormenorizado de las representaciones rupestres, pues se ha puesto más énfasis en algunos aspectos y menos en otros, situación que es contraproducente, dado el objetivo de abordar la dinámica social en su conjunto, a través de los distintos periodos de nuestra historia.

Es así que a través del estudio del uso del espacio podremos aproximarnos más a explicar la naturaleza de estas evidencias, teniendo en cuenta las recurrencias respecto de su ubicación, disposición, cercanía, etc., información que podrá dar nuevos visos acerca de las posibles razones que empujaron a utilizar estos espacios para la representación de dichos elementos, es decir que a través de este tipo de análisis podremos vislumbrar lo que quisieron transmitir el o los grupos humanos que plasmaron estas imágenes en piedra.

\section{Quebrada Verde en el contexto costero: algunas ideas al respecto}

La importancia del hallazgo de una nueva zona con evidencias de arte rupestre pictórico en el valle bajo del Río Lurín radica en su escasa presencia en zona costera, situación que sumada a su ubicación en zona de lomas, hace de este tipo de evidencias algo sui generis en este contexto. Si bien Guffroy (1999) nos habla de la prácticamente exclusiva ubicación de sitios de este tipo en zonas alto andinas, en donde el soporte geológico apropiado se da en mayor medida que en la costa, es importante señalar que recoge además información anterior de evidencias aisladas en zona costera como en Lachay y Quebrada Palo. Asimismo otros reportes para la 
Costa Central se han difundido en algunos medios, presentando algunas propuestas en cuanto a su adscripción cronológica e incluso cultural, pero sin llevar a cabo aún estudios sistemáticos (Echevarría López, 1996; Echevarría López y Ruiz Alba, 2006; Morales Castro, 2006). De otro lado, para el caso de la Costa Norte, el hallazgo de las evidencias rupestres en Cerro Ochipitur se suma al conjunto de evidencias hasta ahora conocidas para la zona costera (Castillo Benites, 2006).

Dada la existencia de estas evidencias, consideramos que aún es muy temprano para hacer asociaciones coherentes entre ellas, pues creemos que ello requiere de un análisis sistemático en cada zona para llegar a una comprensión acorde. Este tipo de investigaciones, si bien llevará algún tiempo para madurar, esperamos pueda brindar frutos pronto, dado el interés que han causado estas evidencias en jóvenes investigadores de nuestro medio durante los últimos años.

En el caso de Quebrada Verde, si bien se espera, a partir de este estudio aún en ciernes, proponer una explicación para este caso en específico, no se pretende explicar la naturaleza exacta de las actividades a las que estuvieron ligadas estas representaciones, sino coadyuvar a una visión menos restringida de éstas, fundamentada no sólo en las propias figuras sino también en la distribución de éstas y los lugares en que se encuentran, así como con otras evidencias culturales dentro de un área específica, ampliando y promoviendo una visión más íntegra.

Es así que buscando ampliar la idea preferimos hablar de Espacios de Representación Rupestre (Traslaviña 2006a, 2006b).. Con esto pretendemos brindarle mayor importancia al continente de estas representaciones, pues las consideramos áreas de actividad en tanto que en estos lugares, creemos, se realizó como mínimo una actividad de la que podemos dar cuenta en el caso que reportamos, como es el plasmado de las figuras en roca. En adelante desarrollaremos nuestra propuesta al respecto, así como nuestros avances en este estudio.

\section{Conclusiones preliminares}

Los avances que hemos hecho del registro de la zona de estudio se encuentran aún en un $80 \%$. Dado esto, nuestras conclusiones son referenciales y tendrán que ser complementadas con nuestros sucesivos avances.

De manera general se puede observar que la mayoría de evidencias que presentan datos con los que se puede explicar tentativamente su cronología (cerámica), apunta a una mayor presencia de actividades en la zona durante el Intermedio Tardío (900 d.C.-1450 d.C)., con la probable reocupación en la época colonial y posteriores. Asimismo existen evidencias del Horizonte 
Temprano (800 a.C. - 200 a.C). que se sustentarían con la presencia de evidencias de similares en zonas aledañas como la Quebrada Guayabo.

Es interesante la ubicación de estas evidencias en zona de lomas, que en el caso de los periodos tardíos podría tener relación con el fenómeno Ischma, e incluso con las evidencias tardías de los Caringas, etnía asentada en la margen izquierda del valle en el sitio de Pueblo Viejo-Pucará. Al respecto, los Caringas, son pueblos provenientes de las alturas huarochiranas que se asentaron en las lomas de Lurín, en cuyas construcciones utilizaban la piedra unida con argamasa.

El uso del terreno en la zona, para las evidencias presentadas, se adscribe mayormente a ladera izquierda de Quebrada Verde, ya que, a pesar de las zonas de pendiente pronunciada, existen mayores zonas de menor pendiente que en la ladera derecha. Asimismo se observa que existe la intención de adaptar el terreno a las necesidades de los grupos, prueba de esto es la gran cantidad de terrazas presentes en la zona.

Por otro lado, se observan extensas zonas con restos de valvas de moluscos (conchales), que denotan la importancia de la dieta marina de estos grupos, lo que se evidencia con "choros" y "machas", entre otros. Cabe resaltar que también pudieron aprovecharse otro tipo de alimentos, sin embargo sólo tenemos evidencia clara de moluscos. Dentro de los recursos es obvio el uso de las lomas, el valle y su río (que está a menos de un kilómetro de la zona), los humedales (cercanos a Pachacamac) y el mar para satisfacer sus necesidades, dada la cercanía de todos estos ecosistemas.

Finalmente, respecto a las pinturas rupestres en la zona, aún queda por profundizar el registro de éstas; de esto trataremos en posteriores publicaciones.

\section{REFERENCIAS BIBLIOGRÁFICAS}

BONAVIA BERBER, D. Arqueología de Lurín. Seis sitios de ocupación en la parte inferior del valle. Lima: Publicaciones del Museo Nacional de la Cultura Peruana. 1965.

BONAVIA BERBER, D. Perú: Hombre e Historia. De los orígenes al siglo XV (Vol. I). Lima: Ediciones Edubanco. 1991.

BUENO MENDOZA, R. A. El Antiguo Valle de Pachacamac: Espacio, Tiempo y Cultura. Lima: Editorial Los Pinos. 1982.

CASTAÑEDA MUNGI, J. C. Geología del área de Pachacamac- Manchay. Tesis de Bachillerato inédita, Universidad Nacional de Ingeniería, Lima. 1973

CASTILLO BENITES, D. (). Evidencias rupestres en la margen izquierda del valle de Moche, Perú. En: Arkeos, Revista electrónica de arqueología PUCP, 1 (4). 2006. Consultado el 3 de febrero del 2009, desde http://mileto.pucp.edu.pe/arkeos//images/documentos/ articulos/4-art-epar-dcb.pdf 
ECHEVARRÍA LÓPEZ, G. T. El Arte Rupestre de Lachay: una introducción a su estudio. En: La Universidad Nacional Mayor de San Marcos y el IV Congreso Nacional de Estudiantes de Arqueología (pp. 77-90). Lima: 1996.

ECHEVARRÍA LÓPEZ, G. T. \& Ruiz Alba, E. Quebrada Palo - Lachay, Perú. La percepción y el registro, un caso de descripción rupestre. En: Rupestreweb. 2006. Consultado el 3 de febrero del 2009 desde en www.rupestreweb.info/lachay.html

ENGEL, F.-A. Otras Lomas del Sur Medio - Cuevas de Chilca. In CIZA (Ed)., Ecología Prehistórica Andina. El hombre, su establecimiento y el ambiente de los Andes, la vida en tierras áridas y semiáridas. Lima: CIZA. 1988.

GUFFROY, J. (El arte rupestre del Antiguo Perú (Vol. 112). Lima: Institut Français d'Études Andines, Institut de Recherche pour le Développment. 1999.

HOSTNIG, R. Arte Rupestre del Antiguo Perú. Inventario Nacional. Lima: CONCYTEC. 2003.

INGEMMET. Mapa geológico del cuadrángulo de la Molina, Hoja de Lurín 25-j4, IV NO. Escala 1: 50000. Versión digital. Instituto Geológico Minero y Metalúrgico. 2002.

ICN. Guayabo - Lima Metropolitana, Hoja 25-j IV 43. Escala 1: 10000. Versión impresa. Instituto Geográfico Nacional - Japan Internacional Cooperation Agency. 1992

IGN. Pachacamac - Lima Metropolitana, Hoja 25-j IV 53. Escala 1: 10000. Versión impresa. Instituto Geográfico Nacional - Japan Internacional Cooperation Agency. 1992.

MATOS MAR, J., \& PORTUGAL MENDOZA, J. El Valle de Lurín y el Pueblo de Pachacamac. Lima: Departamento de Antropología, Facultad de Letras, Universidad Nacional Mayor de San Marcos. 1964.

MENDOZA VALDIVIA, A., \& EUSEBIO ROQUE, L. Ecología y Aspectos Sociales de las Lomas de Lurín entre 1991 y 1993. Boletín de Lima, XVI (91-96), 43-48. 1994.

RAVINES, R. Arte Rupestre del Perú. Inventario General. Lima: Instituto Nacional de Cultura. 1986.

RIVERA MANTILLA, H. Geología General. Lima: Universidad Nacional Mayor de San Marcos. 2005.

TRASLAVIÑA ARIAS, T. A. Estudio de Espacios de Representación Rupestre. Una propuesta preliminar. Ponencia presentada en el II Simposio Nacional de Arte Rupestre. 2006a

TRASLAVIÑA ARIAS, T. A. Estudio de Espacios de Representación Rupestre. Una propuesta preliminar. Manuscrito no publicado, Lima. 2006b.

TRASLAVIÑA ARIAS, T. A., \& Morales Castro, C. (). Lomas y Representaciones Rupestres: Apropiación y Transformación de un Espacio Costero. Ponencia presentada en Perspectivas Comparativas Sobre la Arqueología de la Costa Sudamericana. 2007.

UHLE, M. Pachacamac. A reprint of the 1903 edition by Max Uhle. Philadelphia: University Museum Press, University of Pennsylvania. 1991 [1903].

VICHARRA CUADROS, E. Descripción general de la naturaleza geológica de Quebrada Verde in situ. Apuntes realizados en campo por Teddy Abel Traslaviña Arias. 
Teddy Abel Traslaviña Arias es arqueólogo por la Universidad Nacional Mayor de San Marcos. Su desempeño ha comprendido trabajos de campo y laboratorio en proyectos de investigación auspiciados por entidades extranjeras en Pachacamac (Universidad del Sur de Illinois, EE.UU)., Ica (Universidad de Pittsburgh, EE.UU). y Arequipa (Universidad de Vanderbilt, EE.UU).. De otro lado, se ha desempeñado como asistente en el área de colecciones del Museo de Sitio de Pachacamac y ayudante de cátedra en la Facultad de Ciencias Sociales de la UNMSM, habiendo participado, además, como ponente en eventos internacionales realizados en Lima y Trujillo; asimismo se presentó en el $74^{\circ}$ Annual Meeting of The Society for American Archaeology, en Atlanta (EE.UU).

trasla_81@yahoo.com

Recepción: 18 de noviembre 2008. Aprobación: 10 de febrero 2009. 